\title{
Energy Optimization of Bioethanol Production via Gasification of Switchgrass
}

\author{
Mariano Martín, Ignacio E. Grossmann ${ }^{1}$ \\ Department of Chemical Engineering, \\ Carnegie Mellon University Pittsburgh, PA 15213
}

\begin{abstract}
.
In this paper, we address the conceptual design of the bioethanol process from switchgrass via gasification. A superstructure is postulated for optimizing energy use that embeds direct or indirect gasification, followed by steam reforming or partial oxidation. Next, the gas composition is adjusted with membrane-PSA or water gas shift. Membrane separation, absorption with ethanol-amines and PSA are considered for the removal of sour gases. Finally, two synthetic paths are considered, high alcohols catalytic process with two possible distillation sequences, and syngas fermentation with distillation, corn grits, molecular sieves and pervaporation as alternative deshydration processes. The optimization of the superstructure is formulated as an MINLP problem using short-cut models, and solved through a special decomposition scheme that is followed by heat integration. The optimal process consists of direct gasification followed by steam reforming, removal of the excess of hydrogen and catalytic synthesis, yielding a potential operating cost of $\$ 0.41 /$ gal
\end{abstract}

Keywords: Energy; Biofuels; Bioethanol; Process synthesis

\footnotetext{
${ }^{1}$ Corresponding author. Tel.: +1-412-268-3642; Fax: +1-412-268-7139.

Email address: grossmann@cmu.edu (I.E. Grossmann)
} 


\section{INTRODUCTION}

Ethanol from biomass has become one of the most important alternatives to gasoline due to its compatibility with current automobile engines ${ }^{1}$ and to the fact that it can take advantage of the existing supply chain of liquid fuels that is already well established. While the production of first generation ethanol has raised questions regarding its feasibility as an alternative fuel in terms on land, energy demand, water consumption, ${ }^{2-10}$ the so called second generation of biofuels, which does not compete with the food chain, has received worldwide attention with the aim of improving the yield, and reducing the consumption of energy and water. However, currently no process for producing ethanol from lignocellulosic raw materials has been implemented due to existing technical, economic and commercial barriers, ${ }^{11}$ even though cellulosic ethanol can in principle be more effective than corn ethanol as an alternative renewable biofuel. The main reasons are that cellulosic ethanol can greatly reduce the net greenhouse gas (GHG) emissions, as well as potentially provide higher net fossil fuel displacement with a lower price than when using corn as raw material ${ }^{12-13}$.

Two types of process technologies can be used to transform lignocellulosic raw materials into ethanol. The first one is based on the hydrolysis of the raw material to break down the physical and chemical structure of the crops to expose the sugars that are fermented to ethanol. Due to its similarity with the current production of ethanol and the expected lower capital cost, this technology has received the attention of many researchers. ${ }^{14-17}$ The main disadvantage of the hydrolysis of the lignocellulosic material is the fact that lignin cannot be processed, and thus a part of the carbon source of the raw material cannot be used to obtain ethanol. The second technology is based on the gasification of the raw material into syngas which is used to obtain ethanol either via mixed alcohols catalytic reaction or via fermentation. ${ }^{18-21}$ In spite of some recent papers by Piccolo and Bezzo $(2009)^{20}$ for the production of ethanol, either by the hydrolytic alternative ( $\$ 2.2$ /gallon) or gasification followed by fermentation of the syngas ( $\$ 3.2$ /gallon), reports by NREL indicates the possibility of producing ethanol at $\$ 1.22 /$ gallon by catalytic mixed alcohols system and indirect gasification, ${ }^{18}$ or $\$ 1.95 /$ gal with direct gasification ${ }^{22}$. Huhnke (2008)19 also reported the production of ethanol via gasification - fermentation at $\$ 1.2 /$ gal, while the first pilot plants report production costs of $\$ 1 / g a l$. 23 .

In this paper, we consider the conceptual design of the production of ethanol from the gasification of lignocellulosic raw material. To improve the design and the energy efficiency of lignocellulosic ethanol plants via gasification of the raw material, process synthesis and mathematical optimization techniques ${ }^{24-25}$ are used. We 
propose a superstructure optimization approach where we embed the various process units involved in ethanol production, and then consider alternatives for some of the processes. These units are interconnected with potential process streams. The goal is to optimize the energy consumption in the ethanol production process. Using as a basis short-cut models, empirical correlations and experimental data reported in the literature, the optimization of the system is formulated as a mixed-integer nonlinear programming (MINLP) problem, where the model involves a set of constraints representing mass and energy balances and design equations for all the units in the system. The problem is implemented in the GAMS modeling system in order to perform the optimization. The problem is solved using a special decomposition technique for the technologies of gasification, reforming and synthetic path, which leads to reduced nonlinear programming (NLP) subproblems where the composition adjustment, sour gases removal technologies and ethanol purification scheme are selected based on minimum energy consumption. We then replace the distillation columns by multieffect columns, and finally perform heat integration for the resulting process. The heat recovery network together the multi-effect distillation columns further reduces the energy consumption in the plant, and hence decreases the production cost of ethanol. The economic evaluation of the subproblems provides information for the selection of the optimal ethanol production process from lignocellulosic materials. While the reported optimal design requires further validation with rigorous simulation and pilot plant experiments, it nevertheless indicates the potential for achieving a producing cost of $\$ 0.41 /$ gal when accounting for the sale of hydrogen as a byproduct.

\section{OVERALL PROCESS DESCRIPTION}

The process superstructure consists of three different parts, gasification, gas cleanup and preparation and bioethanol synthesis. For the first part, two different technologies are considered: (1) indirect low pressure gasification with steam where the combustion of char in a parallel equipment (combustor) provides the energy for the gasification of the biomass by heating sand which is fed back to the gasifier; (2) direct high pressure gasification of the raw material with steam and oxygen to avoid the dilution of the gas.

The second part comprises technologies to remove solids from the gas as well as other compounds like hydrocarbons, $\mathrm{NH}_{3}, \mathrm{CO}_{2}$ or $\mathrm{H}_{2} \mathrm{~S}$ and to adjust the gas composition. The hydrocarbons are partially removed in the tar reformer where they are either reformed with steam, or partially oxidized. ${ }^{26}$ In the case of the high pressure gasifier, the solids are removed in a ceramic filter and next the gas is expanded generating energy. If the indirect 
lower pressure gasification is used, the solids are removed together with $\mathrm{NH}_{3}$ in a wet scrubber and compressed. In both cases traces of hydrocarbons (HBC) are removed in a Pressure Swing Adsorption (PSA) system with a bed of silica gel. Next, the composition of the gas is adjusted to a $\mathrm{CO}: \mathrm{H}_{2}$ molar ratio of 1. In order to accomplish this, three alternatives are considered: water gas shift reactor, bypass and hybrid membrane/PSA for removal of $\mathrm{H}_{2}$ (with a bed of oxides). The selection depends on the performance of the gasifier and the tar reformer. Reverse water gas shift reaction to generate more $\mathrm{CO}$ in case of excess of hydrogen has not been considered due to the high price of hydrogen and to the extreme conditions in the reverse gas water shift reaction (temperatures above $650 \mathrm{C}$, and conversions around 50\%). Furthermore, it is more profitable to sell any excess of hydrogen. Sour gases such as $\mathrm{CO}_{2}$ and $\mathrm{H}_{2} \mathrm{~S}$ are removed next. In the case of using catalytic synthesis of ethanol, there should be only ppm's of $\mathrm{H}_{2} \mathrm{~S}$ due to its poisoning effect on the catalysts that are used to produce ethanol. In contrast, fermentation with bacteria can handle up to $2.5 \%$ in volume of $\mathrm{H}_{2} \mathrm{~S}$. The three technologies considered for removing the sour gases are: (1) the absorption of the sour gases in Monoethanolamine (MEA), (2) a PSA system, and (3) the use of a membrane permeable to $\mathrm{CO}_{2}$ and also using MEA as carrier. Selexol is another possible technology, but the solvent is more expensive and more suitable for higher pressures than the ones used in this process.

Finally, two synthetic paths are considered. The first option is the fermentation path where the syngas is fermented in a stirred tank reactor. The unreacted gases are recycled to the gas cleanup section of the process. The water must be removed from the ethanol-water solution to obtain fuel quality ethanol. A beer column removes a large amount of water in the diluted solution of ethanol. In the next step four technologies are considered to dehydrate the ethanol: (1) azeotropic distillation, (2) adsorption in corn grits, (3) use of molecular sieves and (4) pervaporation. The second path for the synthesis of ethanol is the high alcohols synthesis production. ${ }^{18}$ The light hydrocarbons and the unreacted gases are recycled back to the cleanup section of the process The purification of ethanol is carried out using a sequence of distillation columns. Two sequences are evaluated, direct and indirect. Figure 1 shows the superstructure with all the alternatives that are considered.

Figure 1.- Superstructure flowsheet for the production of lignocellulosic ethanol via gasification. 


\section{MATHEMATICAL MODELING.}

All the operations in the ethanol production process are modeled with short-cut equations and empirical correlation that are implemented in the GAMS modelling system. Due to the large number of equations, they are presented in the supplementary material. In the following sections we describe the main ideas and considerations for each of the units as well as the main assumptions for their modelling. The model is written in terms of total mass flows, component mass flows, component mass fractions, and temperatures of the streams in the network. The components in the system include those present in the lignocellulose plus those produced during the process of ethanol production. The complete set of components is as follows $J=\left\{\mathrm{H}_{2} \mathrm{O}, \mathrm{EtOH}, \mathrm{MetOH}, \mathrm{PropOH}, \mathrm{ButOH}\right.$, PentOH, $\mathrm{C}_{6} \mathrm{H}_{6}, \mathrm{MEA}$, Tars, $\mathrm{CO}_{2}, \mathrm{CO}, \mathrm{O}_{2}, \mathrm{~N}_{2}, \mathrm{H}_{2}, \mathrm{H}_{2} \mathrm{~S}, \mathrm{NH}_{3}, \mathrm{CH}_{4}, \mathrm{C}_{2} \mathrm{H}_{2}, \mathrm{C}_{2} \mathrm{H}_{4}, \mathrm{C}_{2} \mathrm{H}_{6}, \mathrm{SO}, \mathrm{C}, \mathrm{H}, \mathrm{O}, \mathrm{S}, \mathrm{N}$, Olivine, Char, Ash \}. Adiabatic mixing is assumed across the process.

\section{Pretreatment}

The elementary composition of the biomass in wet basis is: Water $15 \%$, carbon $40.16 \%$, hydrogen $4.73 \%$, oxygen $34.59 \%$, sulfur $0.07 \%$, nitrogen $0.49 \%$ and ash $4.96 \%$; see supplementary material for further details. The biomass is pretreated before gasification. Figure 2 shows part of the flowsheet related to feedstock pretreatment. Three unit operations are considered, washing, drying and size reduction.

Figure 2.- Pretreatment

The incoming feed of switchgrass (from source Src1) is washed first with freshwater (from source Src2) in a washing unit (Wash). This step removes dirt and dust from the grass. A small amount (1\%) of the wash water is assumed to stay in the grass. The spent washing water is treated and then reused in other processes within the plant, although this option is not considered in the model. It is assumed that $0.5 \mathrm{~kg}$ of washing water is needed to wash $1 \mathrm{~kg}$ of switchgrass. The washing step does not consume any heat because it takes place at ambient temperature. Later, the grass is partially dried by means of a mechanical press that removes $90 \%$ of the water accompanying the grass. A drier using the gas from the gasifier could also be used. Finally, in order for the gasification to be effective, the size of the grass is reduced with grinding as the selected technology. The particle 
size required is around $10 \mathrm{~mm}$, larger than in the case of hydrolysis production of ethanol from switchgrass. Thus, the energy required is also smaller, $30 \mathrm{kWh} / \mathrm{t}{ }^{27}$.

\section{Gasification}

Among the different alternatives that are available for gasification, ${ }^{28}$ we consider the two most common ones, indirect gasification and direct gasification. Figure 3 shows the superstructure for the gasification alternatives. Direct gasification works at high pressure and requires pure oxygen and a large amount of steam, but it produces gas with lower concentration of hydrocarbons that reduces the cost of further compression for clean up stages. On the other hand, the indirect gasification works at low pressure requiring less steam and air can be used for the combustion without diluting the gas since it takes place in a different equipment, but the gas obtained contains a higher concentration of hydrocarbons. In the next sections we outline the assumptions for modelling each of the two alternatives.

\section{Figure 3.- Gasification alternatives}

Indirect Gasification: The operation of the gasifier is based on the one presented by Philips et al $(2007)^{18}$ since their raw material also involves lignocellulosic materials. For the indirect gasification, see Fig. 3 , the switchgrass from the pretreatment stage enters gasifier 1 together with steam (from $\mathrm{Src} 7$ in Fig. 3) and sand (recycled from the combustor). The amounts of steam and sand injected are calculated as a function of the dry biomass providing the energy for the gasification. ${ }^{18}$ According to the literature ${ }^{18}$ it is assumed that the gasifier works at $890{ }^{\circ} \mathrm{C}$ and 1.6 bar, and the combustor works at $995{ }^{\circ} \mathrm{C}$. The basic procedure to determine the gas composition are based on the work by Philips et al. $(2007)^{18}$ and can be seen in the supplementary material.

The solids, mainly char and olivine, are removed from the gas stream exiting the gasifier in a cyclone, Cyc 1. The gas is sent to the reformer. The solids go to the combustor where the combustion of the char takes place providing the energy to reheat up the sand. The energy generated by the combustion of char is around $25000 \mathrm{~kJ} / \mathrm{kg}$ of char $^{29}$

Since the combustion of the char takes place in a different chamber (the combustor), air (from Src 5 in Fig. 4) can be used. Air is injected in $20 \%$ excess of the stochiometric ratio and with $70 \%$ humidity. The air is preheated to $200^{\circ} \mathrm{C}$ in heat exchanger 11 (HX11) before entering the combustor. Make-up sand must also be 
injected in the combustor due to the losses in the cyclones (from $\operatorname{Src} 6$ ). The solids exiting the combustor, mainly olivine, are removed from the gases in a cyclone (Сус 2) and recycled to the gasifier to provide energy for the gasification. The gas exiting the combustor contains the ash from the char as well as the products from the oxidation of the $\mathrm{S}$ and $\mathrm{C}$. Nitrogen is also generated from the char. The particles are removed from the gas before

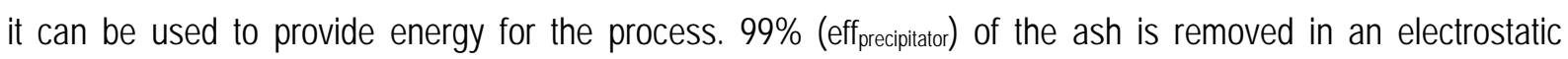
precipitator as well as all the olivine that has been dragged by that stream. Finally, the gas from the electrostatic precipitator is cooled down in heat exchanger 3.

Direct Gasification: The design of the direct gasifier is simpler than the indirect one (see Fig. 3). The biomass from the pretreatment stage is fed to the gasifier 2 together with oxygen (from Src3) and steam (from Src 4). The amounts required are determined from experimental results from a pilot plant gasifier by Gissy et al $(1992)^{30}$. Since the gasifier operates at high pressure $\left(21\right.$ bar and $853^{\circ} \mathrm{C}$ ), oxygen must be compressed. The energy required by the compressor is calculated assuming polytropic behaviour. The gas exiting the gasifier 2 is cleaned from solids in Cyclon 3. Further explanation can be found in the supplementary material.

\section{Hydrocarbon removal}

There are two main alternatives for decomposing the hydrocarbons generated during the gasification process, steam reforming and partial oxidation. The first one produces more hydrogen but is endothermic reducing the energy available within the process. Partial oxidation is exothermic providing energy to the system but the production of hydrogen is lower. We model the removal of hydrocarbons using both alternatives. Other processes that are not considered are dry reforming by using $\mathrm{CO}_{2}$ instead of steam or oxygen, or auto-thermal reforming. ${ }^{26}$ Fig. 4 shows the detail of the gas cleanup flowsheet.

Steam reforming: The gas coming from the gasifiers is fed to the reformer at the same temperature as the outlet from the previous equipment, either low pressure or high pressure gasifier. The tar reformer can work at low or high pressure. ${ }^{31}$ For steam reforming, the chemical reactions taking place are of the form given by eq (1):

$$
\mathrm{C}_{\mathrm{n}} \mathrm{H}_{\mathrm{m}}+\mathrm{nH}_{2} \mathrm{O} \longrightarrow n C \mathrm{CO}+\left(\frac{m}{2}+n\right) H_{2}
$$

while the decomposition of ammonia is as follows:

$$
\mathrm{NH}_{3} \longrightarrow \frac{1}{2} \mathrm{~N}_{2}+\frac{3}{2} \mathrm{H}_{2}
$$


Thus, the mass balances for the different species are determined based on the stoichiometric relationships derived from eqs. (1) \& (2). The conversions of the different hydrocarbons (Conv_i) are taken from the literature ${ }^{18}$ : Conv_CH4 $=0.8$, Conv_C6H6 $=1$, Conv_Tar $=1$, Conv_C2H6 $=0.99$, Conv_C2H2 $=0.90$, Conv_C2H4 $=0.90$ and for the ammonia Conv_NH3 $=0.90$. All these reactions are endothermic. We assume that the reactor operates adiabatically and that the final temperature is reduced to provide energy for the reactions due to the complexity of providing energy directly to the catalytic bed. ${ }^{18}$

Figure 4.- Gas clean up

Partial Oxidation: For the removal of hydrocarbons using partial oxidation, pure oxygen is used (from Src 17 in Fig. 5). The amount of oxygen injected is calculated from the stoichiometric ratio. The mass balances of the species in the tar are calculated based on the chemical reactions of partial oxidation in the form of eq. (3). The conversions of the different hydrocarbons (Conv_i) are assumed to be the same as before based on experimental and computational results from the literature 70,71

$\mathrm{C}_{\mathrm{n}} \mathrm{H}_{\mathrm{m}}+\frac{n}{2} \mathrm{O}_{2} \longrightarrow n \mathrm{CO}+\frac{m}{2} \mathrm{H}_{2}$

\section{Clean up}

Two different possibilities are considered to remove the solids from the gas: the so called hot and cold cleaning. ${ }^{32}$ In case of operating at high pressure, hot cleaning is used. If the operation is at low pressure, cold cleaning is considered. See Fig. 4 for a detail of the flowsheet.

Hot cleaning: The stream coming from the high pressure direct gasifier via the reforming stage is cleaned to remove the solids in a ceramic filter. To use the filter, the gas is first cooled to $500{ }^{\circ} \mathrm{C}$ by means of heat exchanger 5 (HX5). In the filter, only the solids (char, olivine) are eliminated. The short-cut model for the filter is given as function of the solids recovery, which is equal to 1 for char and olivine, and 0 for the rest of compounds. The gases leaving the filter are expanded before entering the hydrocarbon removal system. In this way the gas at high pressure provides energy through its expansion. The expansion is assumed to be polytropic to calculate the final temperature of the gas and the work that is extracted. In case the catalytic path is selected, 
the recycled stream coming from the catalytic reactor system exists; otherwise it is defined as 0 . The mixing between the stream from the catalytic reactor and the expansion is fed to heat exchanger $6(\mathrm{HX6})$.

Cold cleaning: The stream coming from the indirect gasifier is cleaned at low pressure. Then, the gas is cooled down to $40^{\circ} \mathrm{C}$ in heat exchanger 5 (HX5), and as a result, water condenses. The amount of condensed water is calculated based on the saturation moisture at $40{ }^{\circ} \mathrm{C}$ and 1.2 bar. Then, that stream is fed to the scrubber. The amount of water needed for the scrubber $(L / G)$ is calculated using rules of thumb from the literature, $L / G=0.25 \mathrm{~kg}$ per $\mathrm{m}^{3}$ of gas..$^{33}$ Water is fed to the scrubber at atmospheric temperature, $20{ }^{\circ} \mathrm{C}$. In the scrubber, solids (Ash, Char, Olivine) and $\mathrm{NH}_{3}$ are eliminated, while the gas exits the scrubber with a humidity calculated based on saturated conditions. The temperatures of the streams exiting the scrubber are determined by an energy balance considering that the equipment operates adiabatically. The stream coming out of the scrubber is saturated with water and is compressed to the working conditions of the PSA system, 4.5 bar ${ }^{32}$, in compressor 1 . The compression is modeled as polytropic to calculate the final temperature and the energy required. In case the catalytic path is selected, the stream coming from the reactor exists; otherwise it is defined as 0 . The mixture of both streams is fed to heat exchanger $6(\mathrm{HX} 6)$.

PSA - Hydrocarbon removal: The trace of hydrocarbons that has not been eliminated in the reformer are withdrawn from the gas stream using a PSA system as seen in Fig. 4. The typical working conditions for PSA systems are low temperature $\left(25^{\circ} \mathrm{C}\right)$ and moderate pressure ( 4.5 bar) so that there is adsorption of the different components ${ }^{32}$. Typically, a bed of silica gel is the most appropriate for the removal of hydrocarbons (HBC). For all PSA systems we assume that the heat of adsorption is used to desorb the products. Due to the low temperature, more water condenses in heat exchanger $6(\mathrm{HX} 6)$ that is discharged from the system. We assume that the PSA will retain any hydrocarbon left in the gas stream as well as the ammonia. Thus, the efficiency in the removal is 1 for hydrocarbons, ammonia and nitrogen, and 0 for the rest.

\section{Composition adjustment}

Figure 5.- Composition adjustment.

Once the main contaminants are eliminated, the composition of the gas must be adjusted so that the molar ratio between $\mathrm{CO}$ and $\mathrm{H}_{2}$ is 1 . In the case of the fermentation path, a fixed molar ratio is not necessary for 
the process. However, given the economics of the byproducts, it is desirable to separate the excess of hydrogen as it will be shown later in the paper. Fig. 5 shows the three alternatives considered for this task. Splitter 1 determines the fraction of incoming stream that is treated in each alternative. The first alternative is the use of water gas shift (Reactor 1 ) to produce more $\mathrm{H}_{2}$ in case it is necessary at the cost of heating up the stream and injecting steam to the reactor. The second one is just a bypass. The third alternative consists of a hybrid membrane/PSA system to remove hydrogen. This surplus of hydrogen can be sold to increase the profitability of the process ${ }^{34-35}$. In case the fermentation path is selected, the unconverted gas is mixed in Mix 13 with the stream coming from the gas clean up section before the composition is adjusted. Otherwise, the stream from the fermentor is defined as 0 .

Water gas shift: The reaction that takes place in the water gas shift reactor is as follows:

$\mathrm{CO}+\mathrm{H}_{2} \mathrm{O} \leftrightarrow \mathrm{CO}_{2}+\mathrm{H}_{2}$

The conversion depends on the molar ratio between water and $\mathrm{CO}$ and the reaction temperature. Using the experimental data presented by Choi et al. $(2003)^{35}$ we developed a reduced order model to predict the conversion as function of both parameters so that the model can be solved in the steady state. The optimization determines the addition of steam (from Src15) as well as the temperature of the reaction controlled by HX 8 to minimize the energy consumption while adjusting the $\mathrm{CO}: \mathrm{H}_{2}$ ratio. The products of the reactor are calculated as a function of the conversion in the reactor, and the energy involved in the reaction is given by the heat of reaction and the conversion.

Bypass: The bypass is modelled simply by the split fraction that goes to this alternative stream.

$\mathrm{H}_{2}$ PSA / Membrane system: The stream to be treated in the hybrid membrane/PSA system with a bed of Zeolite $13 \mathrm{X}$ for the recovery of hydrogen has to be set to a temperature of $25^{\circ} \mathrm{C}$ and a pressure of $4.5 \mathrm{bar}$, assuming that the inlet pressure is $0.9 \cdot P_{\mathrm{PSA}}$ due to the pressure drop in the previous PSA system. Thus, the gas is re-pressurized to 4.5 bar and cooled down to $25^{\circ} \mathrm{C}$. Water condenses at $\mathrm{HX} 10$ while the gas phase carries water saturating it. New hybrid PSA-membrane systems have been developed to improve the purity of the separation ${ }^{36}$. In this system, it is assumed that only hydrogen is recovered from the gas stream while the other gases pass through and condensed water is removed from the system. Finally, the streams coming from the 
WGSR, the bypass and the PSA-membrane system are mixed. At this point the molar ratio between the CO and the $\mathrm{H}_{2}$ must be 1 .

\section{$\mathrm{CO}_{2}$ and $\mathrm{H}_{2} \mathrm{~S}$ removal.}

The removal of $\mathrm{CO}_{2}$ and $\mathrm{H}_{2} \mathrm{~S}$ is the last cleaning stage for the preparation of syngas. Fig. 6 shows the superstructure for the removal of sour gases from the synthesis gas

Figure 6.- Sour acid gases removal superstructure

. Three different alternatives that can work in series or in parallel are considered. The first alternative is the absorption of $\mathrm{CO}_{2}$ and $\mathrm{H}_{2} \mathrm{~S}$ in monoethanolamine (MEA). ${ }^{37}$ In this method, there is a chemical reaction between the sour gas and the amine. We assume that it is possible to remove all the $\mathrm{H}_{2} \mathrm{~S}$ present in the gas (considering that the ppm's required by the catalyst are within the absorption limit) ${ }^{18}$ as well as the $\mathrm{CO}_{2}$, but it operates at high pressure and requires high energy to regenerate the MEA. The second alternative is the use of a PSA system using a bed of Zeolite $5 \mathrm{~A}$ capable of removing $\mathrm{CO}_{2}$ from the stream ${ }^{38}$. However, the $\mathrm{H}_{2} \mathrm{~S}$ does not adsorb as it requires special coating ${ }^{39}$. The third process consists of the use of a membrane that is porous to $\mathrm{CO}_{2}$. This alternative does not eliminate $\mathrm{H}_{2} \mathrm{~S}$. It requires high pressure and the MEA that is used as a carrier for the $\mathrm{CO}_{2}$ permeated though the membrane ${ }^{40}$ has to be regenerated requiring a large amount of energy. The two different synthetic paths require different gas purities in terms of $\mathrm{H}_{2} \mathrm{~S}$ concentration. $\mathrm{H}_{2} \mathrm{~S}$ is toxic for the catalysts used for the production of ethanol, and therefore it has to be completely removed from the gas. ${ }^{18}$ However, the bacteria can handle up to $2.5 \%$ of $\mathrm{H}_{2} \mathrm{~S}$ in the gas. ${ }^{41}$ Therefore, it is expected that different purification paths be chosen depending on the synthetic path.

MEA system: In this system three streams are treated: the one coming from splitter 4 (Spl4), (the PSA system for the removal of $\mathrm{CO}_{2}$ ), the one from Spl2 (the composition adjustment stage), both mixed in Mix 2, and that from the membrane separation (Spl5). The removal of $\mathrm{CO}_{2}$ and $\mathrm{H}_{2} \mathrm{~S}$ using MEA in Col 1 typically operates at $29^{\circ} \mathrm{C}$ and at elevated pressure, 29 bar 18,37,42-44. The stream coming from Mix 2 is at 0.9 PPSA. Due to the required increase in the pressure, from 0.9 P PSA $_{\text {to }} 29$ bar, a two stage system with intercooling is used. Thus, the 
temperature after each of the compressors is calculated assuming polytropic behavior taking into account that the pressure ratio is the same at each compression stage. The intercooling required is that for which the inlet temperature is equal to that of the first compressor. Once the gas is at the desired pressure, 29 bar, it has to be cooled to $29^{\circ} \mathrm{C}$. Thus, water condensation is likely. The condensed water is separated in Flash 3 to avoid the dilution of the solution of MEA. The gas is saturated with water before entering the column. The stream from Flash 3 is mixed with that from Spl5 and fed to column 1. The total amount of solution of MEA needed to absorb the $\mathrm{H}_{2} \mathrm{~S}$ and the $\mathrm{CO}_{2}$ from the gas stream is calculated as a function of the amount of sour gases eliminated with a molar ratio of 1:1 between the sour gas and the amine. According to GPSA (2004) $)^{37}$, the concentration of solution will be $25 \%$ and a correction factor of 0.40 is used. The solution of MEA used in Column 1 comes from two sources: the regeneration column (Column 2) and some make-up solution due to losses in the regeneration. In heat exchanger ( $\mathrm{HX} 11)$ we adjust the temperature of the mixing of both sources to $29^{\circ} \mathrm{C}$. In column 1 the MEA solution is placed in contact with the gas phase. The efficiencies for the recovery of sour gases are assumed to be 1 for $\mathrm{H}_{2} \mathrm{~S}$ and 0.9 for $\mathrm{CO}_{2}$. The sour gases react with the MEA and are withdrawn from the gas phase. The temperature of the streams exiting column 1 is calculated assuming adiabatic behavior of the column. The gas phase coming out of column 1 is calculated based on the separation efficiencies.

The solution of MEA with the sour gases, coming from column 1 and/or from the membrane system, is mixed (Mix 5) and treated in a distillation column (Col 2) with partial condenser to regenerate the amine. We also assume that the absorbed gases do not contribute to the heat capacities since they are part of the chemical structure of the MEA. The operation of column 2 is based on experimental data and design conditions provided by GPSA ${ }^{37}$ and Nexant Inc. ${ }^{42-44}$. The inlet temperature to column 2 is $\mathrm{T}_{\text {col2 }}=93^{\circ} \mathrm{C}$. Thus, $\mathrm{HX} 12$ is used to heat the liquid up to $93{ }^{\circ} \mathrm{C}$. The temperature at the bottom of the column is $T_{\text {MEA_boil }}=125^{\circ} \mathrm{C}$ while at the condenser it is $T_{\text {MEA_ref }}=54^{\circ} \mathrm{C}$. The heat loads in the heat exchangers of the column are also based on the data provided by GPSA. ${ }^{37}$ From the reboiler, the MEA is regenerated and recycled to heat exchanger $11(\mathrm{HX} 11)$. From the condenser, the gas comprised of $\mathrm{CO}_{2}$ and $\mathrm{H}_{2} \mathrm{~S}$, carries MEA saturating it. In order to calculate the losses of MEA, typical humidification models are used. To determine the amount of MEA that is lost with the gases we assume as an approximation that the MEA solution behaves as water where $\mathrm{P}_{\mathrm{Col} 2}=1.7$ bar. Some of the MEA is lost with the sour gases, which are saturated with MEA. Thus, a makeup of MEA is required from Src 9. 
The outlet gas stream from column 1 can be fed to any other of the $\mathrm{CO}_{2}$ recovery systems, PSA or membrane, or it can be sent to the synthetic part of the process. Splitter 3, determines the fraction of the gas that is fed to any other process unit. The split fractions can take any value between 0 and 1 . For the stream that goes to the reaction part of the process (Spl3, Expcom3) there are two possibilities that are activated depending on the selected path, either fermentation or catalytic synthesis:

Catalytic path: In this case the ratio between the final pressure, 68 bar, and the initial one , 29 bar, being less than 5 indicates that only one compressor is needed.

Fermentation path: In this case there should be an expansion of the base from the initial pressure, 29 bar, to the final pressure, 2 bar. The ratio between both indicates that a system of 3 expanders with inter heating is needed.

$\mathrm{CO}_{2}$ PSA system: The second alternative to remove sour gases is a PSA unit. The streams to be treated using this system are the ones coming from Splitter 2 and the gas phase from column 1 (Col 1). The stream from splitter 2 (Spl2) is recompressed to 4.5 bar, while the one coming from Spl3 must be expanded from 29 bar to 4.5 bar. For this stream, the ratio between the initial and final pressure for the stream coming from the column1 suggests a system of 2 expanders with interheating. Once both streams are at the same pressure, they are mixed. Later, the temperature must be adjusted to $25^{\circ} \mathrm{C}$. Heat exchanger $(\mathrm{HX} 15)$ is used to cool down the gas where the water may condense. The condensed water is separated from the gas exiting the heat exchanger, which is saturated, before entering the PSA bed.

The gas stream exiting the heat exchanger is fed to the PSA system. The system is modeled as two beds in parallel, one operating and the second one in regeneration to allow continuous operation of the plant. The recovery of the PSA system is assumed to be $95 \%$ for $\mathrm{CO}_{2}$ and $0 \%$ for any other gas of the mixture. ${ }^{37,45}$ However, water vapor is present saturating the $\mathrm{CO}_{2}$, and it is absorbed too. Once the majority of $\mathrm{CO}_{2}$ has been removed, the outlet of the PSA system can be fed to the reaction system or recycled back to the MEA system, to Mix 2, for the removal of $\mathrm{H}_{2} \mathrm{~S}$. Splitter $4(\mathrm{Spl} 4)$ determines the fraction of the stream coming out of the PSA system that follows each alternative. This decision depends on the synthetic path. For the catalytic path, $\mathrm{H}_{2} \mathrm{~S}$ must be almost completely removed ${ }^{18}$, which means that the stream exiting the PSA cannot be fed directly to the catalytic reactor. However, if the fermentation path is selected at least part of the stream can be directly fed to the fermentor. Depending on the synthetic path, the adjustment of the process conditions $(T, P)$ is different: 
- Fermentation path: The pressure is reduced from $0.9 \mathrm{P}_{\mathrm{PSA}}$ to 2 bar and interheating is necessary (HX48).

- Catalytic path: The pressure is increased from 0.9 PSA to 68 bar using a system of 3 compressors with intercooling (HX48).

Membrane separation system: The third possibility considers the use of membranes for $\mathrm{CO}_{2}$ removal based on the results by Li et al. ${ }^{40}$ and Olofsson et al. ${ }^{32}$. The stream to be treated is the mixture from splitters (Spl2 \& Spl3). The stream from Spl2 must be compressed to the working pressure $\left(\mathrm{P}_{\text {Memb }}\right)$ of 29 bar. The high final pressure requires that a system of two compressors with intercooling be used. Due to the fact that the membrane system and the MEA system work at the same pressure, the stream coming from Spl3 is already at the proper pressure. Once both streams are at the same pressure they mix. The working temperature at the membrane is $29^{\circ} \mathrm{C}$. Heat exchanger $\mathrm{HX} 16$ is used to cool the stream. After the heat exchanger, water condenses and the gas is saturated of water, which is separated from the gas before it is fed to the membrane system.

In the membrane it is assumed that only $\mathrm{CO}_{2}$ is recovered with an efficiency of $99.9 \%$. The carrier is MEA which is regenerated using column (Col2). The MEA solution with the absorbed $\mathrm{CO}_{2}$ is mixed with the stream coming from Col1 in Mix 5 as we mentioned before. The purified gas can be either fed to the reaction section or recycled for further treatment in the MEA system where the split fraction can take values from 0 to 1 . The treatment of the stream fed to the reactor depends on the synthetic path.

- $\quad$ Catalytic path: A single compressor is enough to adjust the pressure to 68 bar.

- Fermentation path: A system of three expanders with interheating are used due to the high pressure decrease from 29 bar to 2 bar.

The exit streams from the different treatments are mixed before adjusting their temperature to the reactor temperature. Furthermore, a number of constraints must be enforced here. The molar fraction of $\mathrm{CO}_{2}$ must be less that $7 \%$, while the molar fraction of $\mathrm{H}_{2} \mathrm{~S}$ must be less than $2.5 \%$ in case of selecting the fermentation path, or virtually 0 in case of using the catalytic path.

\section{Synthesis}

Two alternatives are considered to produce ethanol from syngas, gas fermentation and mixed alcohol synthesis. The fermentation operates at low pressure and temperature reducing the operating costs, but the 
ethanol must be separated from water, which requires a large amount of energy. The catalytic path operates at high pressure and temperature, which makes its operation expensive even though energy can be recovered by cooling the reactor. The catalytic reaction generates a number of other alcohols reducing the total yield towards ethanol, but the purification of ethanol is energetically less intense and the alcohols can be sold as byproducts. The gas from the previous stages must be heated up to $38{ }^{\circ} \mathrm{C}$, for the fermentation ${ }^{19,41-46}$ or $300{ }^{\circ} \mathrm{C}$ in case of the catalytic path ${ }^{18}$. As shown in Fig. 7, heat exchanger HX17 is used to heat up the syngas.

\section{Gas fermentation and purification.}

Synthesis: Fig. 7 shows the scheme for the fermentation of the syngas and the first stages of purification, solid removal and beer column. The first key issue in the fermentation of syngas is the maximum concentration of ethanol. The best current practice claims a maximum concentration of ethanol in the reactor of $5 \%{ }^{26,47}$. Due to this well known disadvantage, new systems are in development to adsorb ethanol from the water during the synthesis reducing the concentration so that the bacteria can produce more ethano|48. Thus, we have also analyzed the value of $15 \%$ as a critical maximum to evaluate the effect of future improvements in the field and the feasibility of the designs. Water must be fed to the reactor to maintain ethanol concentration below the limit. The stream of water is heated up to the reaction temperature in heat exchanger HX22.

\section{Figure 7.- Syngas fermentation scheme}

Until recently, another issue when generating ethanol from syngas has been the production of acetic acid. In the nineties it was already possible to obtain high selectivity towards ethanol $19,41,46,49$. BRI and Coskata industries have recently reported that their bacteria are capable of producing only ethanol50. The conversion of the $\mathrm{H}_{2}$ (or $\mathrm{CO}$ since $\mathrm{H}_{2}: \mathrm{CO}=1$ ) is about $70 \%{ }^{20}$ The unreacted gas is recycled to Mix13. Based on these assumptions and the stoichiometry of the reaction as in eq. (5), the mass balances for the fermentor are written accordingly.

$3 \mathrm{CO}+3 \mathrm{H}_{2} \longrightarrow \mathrm{C}_{2} \mathrm{H}_{5} \mathrm{OH}+\mathrm{CO}_{2}$

The energy involved in the fermentation process cannot be calculated as a typical reaction due to the consumption of energy due to the growth of cells. Although, results are available in the literature, the ones reporting free energy are the most common. ${ }^{51}$ We assume that the enthalpy of reaction is approximately equal to 
the free energy. For this model, the organic matter is not considered in the mass balances and it is assumed that it is to be separated in the mechanical separation placed after the fermentor. The liquid stream from the mechanical separation is fed to the distillation column Col3, traditionally known as the Beer column. The unreacted gas and the $\mathrm{CO}_{2}$ exiting the reactor is saturated with water. The water leaving the reactor with the liquid ethanol is calculated as the difference between the one that enters and the one that is dragged by the gas. The recycle gas is recompressed in compressor 6 to be mixed at Mix13 in Fig. 5 .

The liquid phase consisting mainly of water and ethanol are fed to the beer column to reduce the water content. We model this column using simple correlations assuming ideal behaviour. The fact that we are working far from azeotropic conditions allow us to use this simplification in this column. The relative volatility of ethanol with respect to water ( $\left.\alpha_{\text {ethanol } / \text { water }}\right)$ is taken to be 2.2389 and is assumed to be constant over the temperature range of the column. Water is chosen to be the heavy key and ethanol the light key for the calculations in both the beer column as well as the rectification column. Hence, the effect of all components except water and ethanol on the condenser temperature is neglected. Furthermore, only ethanol and water are assumed to be present in the vapor distillate stream coming out from the condenser of the beer column, and so only these components are considered to be present in the ethanol purification section. A partial condenser is used in the beer column to obtain a vapor distillate since the molecular sieves and the corn grit adsorption handle vapor mixtures of ethanol and water. In the feed to the beer column and in the reboiler, the effect of the components other than water on the bubble point is negligible since their compositions are extremely small and their mole fractions are also very small. The vapor pressures of water and ethanol are predicted by the Antoine equation. The beer column operates at atmospheric pressure $\left(P_{B C 1}=1 \mathrm{~atm}\right)$, and a pressure drop of $0.1 \mathrm{~atm}$ across the column $\left(\Delta P_{B C 1}\right)$ is assumed. Therefore, the temperature of the inlet stream is calculated at $1 \mathrm{~atm}$, the temperature of the reboiler is computed at $1.05 \mathrm{~atm}$ and the temperature in the condenser is calculated at $0.95 \mathrm{~atm}$.

Both the inlet temperature and the recovery of water are variables in the column operation while the recovery of ethanol is fixed at 0.996 . The maximum concentration of ethanol in the distillate is bounded to be at the most $0.8(\mathrm{w} / \mathrm{w})$ to avoid a large number of plates. The theoretical number of trays of the column is calculated using Fenske's equation ${ }^{52}$ with a relative volatility of ethanol 2.239 . The actual number of trays is calculated assuming an efficiency of $80 \%$. The temperatures of the inlet and outlet streams are calculated based on the bubble and dew points ${ }^{52}$. A partial condenser is used in the beer column to save energy. Thus, the composition 
of the condensed liquid in the distillate (reflux) is not the same as the top product which is removed as saturated vapour. It is assumed that the extracted vapor is in equilibrium with the liquid phase. The composition of the reflux stream can be calculated using the vapor-liquid equilibrium relationship for water and ethanol at the temperature of the condenser. The heat balances in the reboiler and the condenser depend on the reflux ratio. A reflux ratio $\left(R_{-}\right.$col3 $)$of 1.5 is selected for the beer column ${ }^{53}$. Since the recovery of ethanol at the top is fixed at $99.6 \%$, the bottom stream contains almost no ethanol. The relative volatilities of other species with respect to water are very small, so their contributions to the heat of vaporization in the reboiler may be neglected. We also neglect the temperature change in the reboiler.

Dehydration: Fig. 8 shows the superstructure proposed for the dehydratation of ethanol. Four different alternatives, which can be used in parallel or in series are considered for the dehydration of ethanol: rectification, adsorption in corn grits, molecular sieves, and pervaporation. Rectification allows water elimination from moderately concentrated ethanol-water mixtures, but requires a large amount of energy. Adsorption in corn grits is cheap, but it is not capable of dehydrating the ethanol to fuel quality. Molecular sieves is a convenient alternative in terms of energy consumption, but it can only be used if the inlet flow has a water concentration lower or equal to $20 \% \mathrm{w} / \mathrm{w}$. Finally, pervaporation requires interstage heating and a number of stages to achieve fuel quality for the ethanol. Splitter Spl6 divides the stream into the four alternatives.

Distillation: Since the azeotropic composition of an ethanol-water mixture at atmospheric pressure is about $95 \mathrm{wt} \%$ of ethanol, this is the maximum achievable purity of ethanol in an atmospheric rectification column. The required purity for fuel grade ethanol is much higher, so the mixture must be further dehydrated. The rectification column is modeled in a similar way as the beer column in terms of pressure drop and vapour-liquid equilibrium. A partial condenser is used in this column so that this stream can be fed to the other dehydration technologies. The ethanol recovery is fixed at $99.6 \%$ and the recovery of water at the top of the column is selected to be a variable while maintaining the azeotrope composition as the maximum achievable purity. Furthermore, it is assumed that only water is vaporized in the reboiler. However, a reflux ratio of 5 is selected so that the column design is feasible due to the fact that the operation is close to the azeotrope. The outlet of the column does not meet fuel quality specifications. Thus, the stream has to be further treated in order to dehydrate it. Splitter Spl7 divides the stream so that it can be fed to the adsorption system, the molecular sieves or the pervaporation system where the split fraction takes values form 0 to 1. 
Figure 8.- Ethanol dehydration superstructure

Adsoprtion corn grits: The feed for the adsorption unit (Ads1) can come from the rectification column as well as from the beer column. Some researchers have investigated the use of biomaterials as absorbents ${ }^{54,55}$. A bed made of corn grits (composition shown in Table ${ }^{55}$ ) selectively adsorbs water from an ethanol-water vapor mixture coming from mixer Mix5.

The corn grits for this bed come from a source unit (Src11 in Fig. 8 ). Heat exchanger HX33 heats the corn grits to the adsorption temperature ( $T_{-}$ads). The bed adsorbs water from the ethanol-water vapor mixture and the ethanol is directed to splitter Spl8. The ethanol-water mixture rises to the bed temperature as the water adsorbs into the bed. The maximum concentration of ethanol obtainable at the outlet of the bed is assumed to be $97.7 \%$ with a recovery of $90 \% \mathrm{w} / \mathrm{w} .{ }^{56}$ After the bed is saturated with water, the vapor can be sent to splitter Spl8, and from there to either mixer Mix8 or Mix 10, while fresh adsorbent enters the column and a new adsorber bed is formed. An alternative scheme is to use two corn grit beds working in parallel, one being saturated with water while the other is being dehydrated (or regenerated). For the costing analysis of the overall plant, we consider a dual-bed corn grit adsorber, and the energy cost for the regeneration of the bed is taken into account. The products from this process can be fed either to the molecular sieves or to the pervaporation system. Splitter Spl8 determines this separation where the split fraction can take values between 0 and 1 .

Table 1. Data for adsorption on corn grits

Molecular sieves: Molecular sieves are a very common technology that is used to selectively adsorb water from an ethanol-water mixture and obtain near $100 \%$ pure ethanol, which is fuel quality. The feed for the molecular sieves can come from the outlet of the corn grit bed adsorber or from the distillation columns, and these streams are mixed in mixer Mix8 to generate an inlet stream for the molecular sieve MS7. There is a lower bound on the fraction of ethanol entering the molecular sieve (0.8). Adsorption takes place at $95{ }^{\circ} \mathrm{C}$ and at atmospheric pressure. Heat exchanger $H X 34$ heats the inlet stream from the mixer Mix 8 up to $95{ }^{\circ} \mathrm{C}$. The molecular sieve is a bed of zeolite that operates in semi-continuous mode. The bed is saturated with water after a period of time and is then regenerated. Hence, there are usually two sieves being operated in parallel - one being saturated with water (MS7) while the other (MS8) is being regenerated (or dehydrated) using air under vacuum. 
Heat exchanger $H X 35$ heats air with an assumed relative humidity of $70 \%$ at $20{ }^{\circ} \mathrm{C}$ to $95{ }^{\circ} \mathrm{C}{ }^{53}$. The air at the outlet of the dehydrating molecular sieve is cooled down to $25^{\circ} \mathrm{C}$ in heat exchanger $H X 36$, and this stream leaves this exchanger saturated with water at $25^{\circ} \mathrm{C}$. The data used in the model for the molecular sieves is taken from Jacques et al. (1999) $)^{57}$ and is summarized in Table 2.

Table 2. Data for molecular sieves

Pervaporation: The performance of perevaporation is determined by the degree of separation of the fluid mixtures and the permeation rate (flux). Pervaporation membranes are usually composites. The first layer is a porous, polymeric support coated with a second polymer, the "active" or "permselective" layer, which is engineered to preferentially absorb the chemical species of interest. The membranes' separation characteristics can be further refined by varying the thickness of the permselectvity layer. For the purpose of the pervaporation module in the bio-ethanol plant, hydrophilic membranes need to be used since water needs to be removed. A three pervaporation system is considered ${ }^{58}$. It can receive flows from the rectification column, the corn grit adsorption unit or the molecular sieves. In mixer (Mix10). Each effect works at $90^{\circ} \mathrm{C}$, thus $\mathrm{HX} 40$ is used to adjust the inlet temperature. The maximum water composition at the inlet is $15 \%$. The water recoveries are $0.95,0.97$ and 1 in each of the effects respectively ${ }^{58}$. In each of the effects the energy to evaporate the water is obtained from cooling down the liquid stream. Thus, reheating is needed between effects to heat up the stream again up to $90^{\circ} \mathrm{C}$ by means of $\mathrm{HX} 41$ and $\mathrm{HX} 42$ for the second and third effect, respectively.

Final product: The ethanol with fuel quality is condensed and/or just cooled down to $25^{\circ} \mathrm{C}$ in $\mathrm{HX} 44$.

\section{High alcohols synthesis}

Synthesis: Fig. 9 shows the detail of the flowsheet for the catalytic synthesis of ethanol and the separation of the gases from the liquid products. In the reactor a number of different chemical reactions take place. Their stoichoimetry and the partial conversions of $\mathrm{CO}$ for each of the reactions presented by Philips et al. $(2007)^{18}$ are used to formulate the mass balances for the species in the reactor (the total conversion of CO is 0.594) and are given as follows: 


$$
\begin{aligned}
& \mathrm{CO}+\mathrm{H}_{2} \mathrm{O} \longrightarrow \mathrm{H}_{2}+\mathrm{CO}_{2} ; \quad \text { Con_CO2 }=0.219 \\
& \mathrm{CO}+2 \mathrm{H}_{2} \longrightarrow \mathrm{CH}_{3} \mathrm{OH} ; \quad \text { Con_MetOH }=0.034 \\
& \mathrm{CO}+3 \mathrm{H}_{2} \longrightarrow \mathrm{CH}_{4}+\mathrm{H}_{2} \mathrm{O} ; \quad \text { Con_CH4 }=0.003 \\
& 2 \mathrm{CO}+4 \mathrm{H}_{2} \longrightarrow \mathrm{C}_{2} \mathrm{H}_{5} \mathrm{OH}+\mathrm{H}_{2} \mathrm{O} ; \quad \mathrm{Con} \_\mathrm{EtOH}=0.282 \\
& 2 \mathrm{CO}+5 \mathrm{H}_{2} \longrightarrow \mathrm{C}_{2} \mathrm{H}_{6}+2 \mathrm{H}_{2} \mathrm{O} ; \quad \text { Con_C2H6 }=0.003 \\
& 3 \mathrm{CO}+6 \mathrm{H}_{2} \longrightarrow \mathrm{C}_{3} \mathrm{H}_{7} \mathrm{OH}+2 \mathrm{H}_{2} \mathrm{O} ; \quad \text { Con_PropOH }=0.046 \\
& 4 \mathrm{CO}+8 \mathrm{H}_{2} \longrightarrow \mathrm{C}_{4} \mathrm{H}_{9} \mathrm{OH}+3 \mathrm{H}_{2} \mathrm{O} ; \quad \text { Con_ButOH }=0.006 \\
& 5 \mathrm{CO}+10 \mathrm{H}_{2} \longrightarrow \mathrm{C}_{5} \mathrm{H}_{11} \mathrm{OH}+4 \mathrm{H}_{2} \mathrm{O} ; \quad \text { Con_PentOH }=0.001
\end{aligned}
$$

Figure 9.- Flowsheet for the catalytic synthesis of ethanol

In case there is not enough water for the reactions, it has to be added (from Src 16). The main point is that the condensation of water in previous clean-up stages reduces the water vapor with the gas phase. The energy involved in the synthesis is calculated based on the enthalpies of reaction of products and reactants. In order to separate the gas phase from the liquid phase and to avoid losing liquid, the flash operates at the same pressure as the reactor, but the mixture is cooled down to $30^{\circ} \mathrm{C}$. Under these conditions more that $99 \%$ of the liquids are separated from the gas. The recovery of the flash is considered to be $100 \%$ for the gases and hydrocarbons, and $0 \%$ for the water and the alcohols. The stream is also expanded to atmospheric pressure to help desorb the $\mathrm{CO}_{2}$ from the liquid. The liquid stream as saturated liquid is fed to the columns. Thus, it has to be heated up in heat exchanger HX23 (see Fig. 10). The actual temperature of the inlet stream is calculated in the model for the distillation column.

Purification: Fig. 10 shows the superstructure of the purification of ethanol. Two different sequences for the distillation columns involved in the purification of ethanol are considered, direct and indirect. In the indirect separation ethanol and methanol are separated from the heavier compounds, water, propanol, butanol and pentanol, and later, ethanol and methanol are further separated to obtain fuel quality ethanol. In case of the direct sequence, methanol is separated first, while in the second column ethanol is obtained in the distillate. The methanol recovered is recycled back to the reactor to improve the yield towards ethanol. In order to reduce the energy input to the process, the methanol coming out of the distillation column is condensed. Then, it is pumped and heated up to the reaction conditions. All the columns are modeled in the same way, and similarly to the beer 
column, which is explained in detail in the supplementary material. A molecular sieve system before the columns may be necessary in case a certain amount of water is produced in the reactor. However, the condensation of water in the clean up process reduces the amount of water in the gas. Furthermore, according to the reactions in eqs. (6)-(13), water is consumed not produced, and thus no molecular sieves are considered.

Figure 10.- Superstructure for the production of ethanol

\section{Solution procedure}

The synthesis and heat integration for the production of ethanol from lignocellulosic raw materials is performed in three stages. First, we optimize the structure of the flowsheet using as an objective to minimize the consumption of energy given the concern of energy requirements in biofuel processes $2,18,20$. Second, we carry out the heat integration. Finally we perform a detailed economic evaluation.

For the structural optimization of the problem, the MINLP model of the superstructure, implemented in GAMS 23.2, is decomposed using a hybrid search method. We first decompose the superstructure by means of a partial enumeration of alternatives in terms of gasification, reforming mode and synthetic path, creating a partial tree. More specifically, we fix the gasification technology (low pressure or high pressure), the reforming mode (steam or partial oxidation) and the synthetic path (fermentation or catalytic), which gives rise to eight NLP subproblems of the superstructure $(\mathrm{A}$ to $\mathrm{H})$. Figure 11 shows the tree that arises in that decomposition and Table 3 summarizes the definition of the eight subproblems.

Figure 11.- Decomposition of the superstructure.

Table 3.- Definition of subproblems

The solution of each of the subproblems in Table 3, whose size is of about 7000 eqs. and 8000 variables, involves decisions regarding the technologies used for composition adjustment in terms of $\mathrm{CO} / \mathrm{H}_{2}$ either using WGSR, bypass or hybrid membrane/PSA, sour gases removal (MEA; PSA or membranes), and the purification of the ethanol obtained from fermentation in which case the proper dehydration technologies must be defined, or from catalysis where either the direct or the indirect distillation sequences is to be selected. It is important to mention that for each of the fermentation cases $(B, D, F$ and $H)$ we have also considered two cases: a) the $5 \%$ concentration of ethanol in the fermentor (a current maximum achievable value) or, b) $15 \%$ of ethanol 
concentration in the reactor if the new developments are realized in the future. Thus, together with the fermentation based subproblems $\mathrm{B}, \mathrm{D}, \mathrm{F}$ or $\mathrm{H}$, a note on the ethanol concentration is added to evaluate both cases towards the profitability of the process.

Each of the subproblems consists of three subsystems: (1) composition adjustment for $\mathrm{CO}$ and $\mathrm{H}_{2},(2)$ sour gases $\left(\mathrm{CO}_{2}\right.$ and $\left.\mathrm{H}_{2} \mathrm{~S}\right)$ removal, and (3) ethanol purification, which depends on the synthetic path under consideration. The split fractions are treated as continuous variables. The subsystems are not independent but they are linked by concentration, composition and operating pressure requirements. If not met, the next subsystem cannot operate. For initialization purposes, we first optimize the structure of each of the subsystems sequentially (1) to (3) based on minimum energy consumption to meet the composition, concentration and operating pressure constraints to operated the next subsystem. Several NLP's solvers (MINOS, KNITRO, CONOPT3) are used to initialize the solution of each subsystem. The solution of the subsystems in sequence provides a good initial guess for the solution of the entire subproblem. The solution of each of the subproblems yields eight flowsheets with an optimal configuration of purification and cleanup technologies in terms of energy consumption.

In a second stage, for each of the subproblems heat integration is performed in two steps:

- First, once the flowsheet of each of the subproblems is optimized, the distillation columns are replaced by multieffect columns in each of the alternatives. Based on the studies by Larsson \& Zachi (1996), Haelssig et al $(2008)^{59,60}$, multieffect columns are found to be the most effective distillation systems for reduced energy consumption. Karrupiah et al. (2008) $)^{53}$ also showed the effectiveness of multieffect columns in reducing the energy consumption in corn-based ethanol plants. In these systems, a distillation column is replaced by two or more columns. By operating the columns at different pressures, the condenser of a higher pressure column serves as the reboiler of a lower pressure column. The inlet feed is split between the columns, and their top and bottoms products are mixed together to obtain the final products with the desired flow rates and compositions. A schematic of a triple effect distillation column is shown in Fig 12. In this work we have considered multieffect columns with up to three columns. For determining the fraction of feed to be sent to each column and the operating pressures of the columns, we set up an optimization model to minimize the total annualized cost for the multieffect columns (annualized equipment cost, annual steam cost, annual cooling water cost) subject to the constraint that product compositions at the top and bottom of each column must match the ones obtained for a 
single distillation column from the results of the previous optimization. This is due to the fact that the superstructure has already optimized the heat loads, and this new configuration tries to improve the results. Hence, additional heat exchangers as well as compressors may be required to meet the initial conditions, whose investment cost and utility cost would be included in the total cost. Also, isenthalpic expansion valves are needed for some streams to match the pressure of the low pressure columns.

-Second, once we have replaced the distillation columns by multieffect columns, heat integration of the process is carried out for each one of the eight subproblems under consideration because this leads to considerable savings in the utilities (steam, cooling water) and consequently in the operating costs 52,61 . To carry out the heat integration, the software SYNHEAT (http://newton.cheme.cmu.edu/interfaces) is used with the following procedure. There are one or two streams resulting from the gasification at a temperature higher than high pressure steam that are first used to integrate energy within the process. Once these streams are exhausted, we use SYNHEAT to design the network among the rest of streams. The software is based on the work by Yee and Grossmann (1990)62, and uses an MINLP model that determines a minimum cost network, where the heat exchanger areas and the stream matches are optimized simultaneously, given the heat capacity flowrates of the different streams and the inlet and outlet temperatures of these streams.

The last stage consists of performing a detailed economic evaluation involving equipment cost, raw material, labor and utilities cost in order to select among the 8 subproblems in Table 3 based on the minimum production cost of ethanol.

Figure 12.- Superstructure for the multieffect columns:

\section{RESULTS AND DISCUSSION}

\section{Structural decisions and heat integration.}

The production capacity of bioethanol plants is limited by the availability of biomass in the region. Current trends as well as NREL reports suggest values in the range of 40 to $60 \mathrm{Mgal} / \mathrm{yr}$. Thus, in order to compare our results with the ones reported in the literature ${ }^{18,53}$ the production capacity of the plant was fixed to be $60 \mathrm{Mgal} / \mathrm{yr}$. 
In the first stage, the partial decomposition of the problem gives rise to eight subproblems from the superstructure in Fig. 1, whether the gasifier is direct or indirect, whether the reforming mode is partial oxidation or steam reforming, and finally whether the synthesis is via catalytic reaction or via fermentation. After the problem is divided into the 8 subproblems, the optimization of the each of the subproblems defines process flowsheets where the stages related to adjustment of $\mathrm{CO} / \mathrm{H}_{2}$ composition, sour gas removal and ethanol purification are optimized for the minimum consumption of energy. The solution of the superstructure for the purification stages for all the subproblems can be summarized as follows:

- The surplus of hydrogen generated in the gasifier is removed from the system to be sold using the hybrid membrane-PSA system.

-Regarding the removal of sour gases, the solution found is a process in which PSA is followed by MEA technologies to reduce the energy input needed for the regeneration of the MEA. The synthetic path determines the amount of gas that must be treated in the MEA. In case of the catalytic path, the whole stream coming from the PSA must be treated since $\mathrm{H}_{2} \mathrm{~S}$ is toxic for the catalyst. For the fermentation synthesis, only half the stream is treated to purge the $\mathrm{H}_{2} \mathrm{~S}$ generated in the gasification.

-Finally, in case of the fermentation path, the molecular sieves are the suggested technology to dehydrate the ethanol. For the catalytic path, the indirect distillation sequence is found to be optimal.

In the second stage, once each of the subproblems in Table 3 is optimized for minimum energy consumption, to further reduce the energy needs, multi-effect columns are used and heat integration is performed. Due to the fact that the conversions of the reactors are relatively high (more than 60\%) and that they are fixed based on the current best practices, simultaneous heat integration is not expected to provide a substantial improvement. Thus, heat integration was carried out sequentially. First, multi-effect columns are used for the beer column as well as for the distillation columns for the purification of ethanol in the catalytic path. The design of the multieffect columns involves determining the split fractions as well as the operating conditions of the different effects. Table 4 shows the summary of the operating variables for the columns in the different subproblems. The results reveal that three-effect columns are capable of reducing the energy consumed and the cooling requirements by up to $50 \%$ and $66 \%$ respectively compared to single column operation. In all the cases, the low pressure operates under vacuum ( 0.26 bar), the intermediate pressure is close to atmospheric pressure ( 0.75 bar) and the high pressure column at 2.1 bar. 
Next, heat integration is performed. The next section shows the energy consumption for the eight subproblems with optimized purification stages and the contribution of heat integration and multieffect columns. After heat integration, we still consider eight different alternatives based on the gasifier (indirect or direct), the reforming (steam or partial oxidation) and the synthetic path (fermentation or catalytic). Furthermore, the sensitivity analysis on the effect of the concentration of ethanol in the water in the fermentor is also performed by studying two concentrations, $5 \%$ ethanol in water and 15\% ethanol in water. Finally, in the third stage, we perform an economic study to determine the corresponding the manufacturing cost so that we determine the best option among the subproblems.

Table 4.- Summary of the operating condition of the distillation multieffect columns

\section{Economic evaluation.}

The economic evaluation involves the cost of the raw materials, chemicals, labour, utilities, maintenance and annualized cost of the equipment. The cost of utilities and raw material prices are updated from the ones that are available in the literature $\left(\$ 0.019 / \mathrm{kg}\right.$ Steam, $\$ 0.057 / \mathrm{MT}$ cooling water ${ }^{63}$, Electricity: $\$ 0.06 / \mathrm{kWh}{ }^{64}, \$ 0.021 / \mathrm{kg}$ Oxygen, Switchgrass price: $\$ 30 / M T{ }^{65-66}$ ). The contribution of the production of hydrogen is key for the profitability of the process. The estimations by the $\mathrm{DOE}^{67}$ suggest that the lowest price of hydrogen is $\$ 1.58 \mathrm{~kg}$ which is the value we use in this work. The estimation of the equipment costs can be found in the supplementary material. In the following sections we discuss the energy and raw material consumption and the byproduct credits towards the final manufacturing cost. We present the results in two groups based on the synthetic path used, fermentation or catalytic.

\section{Catalytic. Subproblems $(A, C, E, G)$}

Fig. 13 shows the comparison of the energy (heat and electricity) required for the different alternatives (gasification technologies and reforming) as well as the savings in energy by heat integration when using catalytic synthetic path. The subproblems described the section are labelled as A, C, E and G (see Table 3). For each of the subproblems, three columns are shown in Fig. 13, corresponding to the energy required before heat integration, the energy balance for the process after energy integration and the cooling requirements after energy integration. 
As it can be seen in Fig. 13, heat integration plays a large role in reducing the energy consumed in the process. After structural optimization and heat integration, all the processes produce energy (from 18MW to $67 \mathrm{MW}$ ) either electric energy obtained from the expansion of the gases, and/or thermal energy from the excess of energy generated in the catalytic reactor, which is an advantage compared to corn-based ethanol, which is energy consuming (for this case the electric energy is also added to the thermal energy) ${ }^{53}$. The generation of an excess of steam is considered as revenue at $\$ 0.0077 / \mathrm{kg}_{\text {steam }}$ (updated from Smith and Varbanov, 2005) ${ }^{68}$ while the electric energy is sold at the same price it is bought $(\$ 0.06 / \mathrm{kWh})^{64}$. The high temperatures and pressures result in at least 46MW of cooling needs (subproblem C) compared to the only 20MW required in the corn-ethanol process $^{53}$. The energy consumption results shown in Fig. 13, provide a good idea of the profitability of the processes. However, energy consumption is not enough to decide on the optimal process due to the large contribution of the raw material to the production cost.

The price of the raw material greatly affects the final production cost of ethanol. The cases presented have different conversions to ethanol based on the operation of the gasifier and the synthetic path, which makes them more or less sensitive to the price of switchgrass. Fig. 14 shows the consumption of biomass to produce 60 Mgal/yr of ethanol for processes A, C, E, G. In Fig. 14 it can be seen that low pressure gasification has a higher yield (consumes only $22 \mathrm{~kg} / \mathrm{s}$ vs. $29 \mathrm{~kg} / \mathrm{s}$ of the high pressure gasifier), but in general all the catalytic processes have lower conversion compared to the corn ethanol process (which only consumes $18 \mathrm{~kg} / \mathrm{s}$ ) due to the production of high alcohols.

Figure 13.- Optimized energy consumption (catalytic reactor)

Figure 14.- Raw material consumption (catalytic reactor)

In Table 5 we show the production cost of lignocellulosic ethanol via catalytic path including equipment costs (see supplementary material for a detailed description of the cost correlations used in this work), the different utilities (steam, electricity, oxygen and cooling water) and chemicals (catalysts, MEA,...) as well as the raw material cost and the contribution of the production of hydrogen as byproduct. The sale of higher alcohols such as propanol has not been considered as a revenue due to the lack of purity of each one, while hydrogen is considered as a byproduct at a price of $\$ 1.58 / \mathrm{kg} 67$. The contribution of the raw material to the production cost of ethanol is around $40 \%$ in all cases. In general, the production costs are lower compared to those of corn based 
ethanol53, while the yield obtained with respect to the biomass ( $\left.\mathrm{kg}_{\text {ethanol }} / \mathrm{kg}_{\text {biomass }}\right)$ is in the range of the ones reported in the literature for gasification and catalysis, around 20\% (Wei et al, 2009) ${ }^{69}$, and even better in case of low pressure gasification (subproblems $\mathrm{A}$ and $\mathrm{C}$ ) reaching values of $26 \%$. Before considering the contribution of hydrogen as byproduct, the lowest cost corresponds to subproblem $C$, which uses low pressure indirect gasification and steam reforming, with an operating cost of $\$ 0.87$ /gal. This value is already a promising result that is close to the values announced in the press release by Coskata industries ${ }^{23}$ at $\$ 1 / g a l$. This process generates energy, $40 \mathrm{MW}$, while the raw material consumption, $22 \mathrm{~kg} / \mathrm{s}$, and the cooling water needs, $46 \mathrm{MW}$, are the lowest among the catalytic processes. However, taking into account the sales of hydrogen and its high price, the decision regarding the most profitable process is different. It turns out that the most profitable process is subproblem $\mathrm{G}$ which uses high pressure gasifier followed by steam reforming. It generates only $18 \mathrm{MW}$, it has lower conversion of the raw material towards ethanol (consuming $29 \mathrm{~kg} / \mathrm{s}$ vs. $22 \mathrm{~kg} / \mathrm{s}$ ) and requires $68 \mathrm{MW}$ of cooling (see Fig. 13). However, the production of hydrogen is an important asset of this process. The contribution of hydrogen as byproduct and the energy generated reduces the operating cost from $\$ 1.04$ /gal to a value of only $\$ 0.41$ /gal. Therefore, the large contribution of the production of hydrogen to the economics of the process leads to the conclusion that steam reforming is more attractive than partial oxidation due to the higher production of hydrogen, even though the energy available in the process is lower. Thus, it is the contribution of hydrogen production that makes the production of ethanol from switchgrass via gasification economically attractive.

Table 5.- Operating cost of 60Mgal/yr via catalytic reaction

\section{Fermentation. Subproblems $(B, D, F, H)$}

As in the previous case, we compare the energy consumption for the different subproblems (type of gasifier and reforming mode, see Table 3) when using the fermentation synthetic path. In this case a sensitivity analysis of the effect of ethanol concentration in the reactor is also analyzed since it is key to determining the energy spent in dehydration of the ethanol to fuel quality. The results are shown in Fig. 15. For each of the subproblems we show the energy required for the process before and after heat integration and the cooling requirements after heat integration. The most important problem faced in the fermentation based processes is the low concentration of ethanol in the fermentor.

Figure 15.- Energy optimzation (Fermentation) 
As it can be seen in Fig. 15, under current best practices at the reactor (5\% ethanol in the reactor), most of the processes require around $40 \mathrm{MW}$, similar to the energy consumed by the optimized process for the production of ethanol from corn ${ }^{53}$. It is only when the concentration of ethanol reaches values over $15 \%$ when the energy demands of all the processes fall to values close to 23MW. In general, the cooling needs range from $25 \mathrm{MW}$ to $60 \mathrm{MW}$, lower than in the case of catalytic based process because a large part of the process operates at lower temperatures. However, not only will the energy determine the profitability of the process, but also the consumption of the raw material and the production of hydrogen.

Fig. 16 represents the biomass required for the production of $60 \mathrm{Mgal} / \mathrm{yr}$ of ethanol. The use of indirect low pressure gasifier yields the lowest consumption rates of raw material $(18 \mathrm{~kg} / \mathrm{s})$ similar to the one obtained in the corn-based ethanol process. Furthermore, the yields from raw material to ethanol $\left(\mathrm{kg}_{\text {ethanol }} / \mathrm{kg}_{\text {biomass }}\right.$ ) are in the range of the ones reported in the literature, around $26 \%{ }^{69}$. Even better is the low pressure gasification reaching 33\% which is higher than the processes based on the catalytic synthesis (19\%-25\%). In Table 6 the production costs of ethanol via fermentation of syngas are presented for the different alternatives (the two gasifiers and the two different synthetic paths). The raw material and the production of hydrogen play an important role in the production cost. Before considering the contribution of hydrogen as byproduct, at the current best practice (5\% concentration of ethanol), promising values around $\$ 1 /$ gal are obtained as long as the low pressure indirect gasification is used. These processes, however, cannot compete with the catalytic processes (with an operating cost of $\$ 0.87$ /gal before hydrogen contribution) unless the concentration of ethanol in the reactor reaches values above $10 \%$. The main difference compared to catalytic based processes is the higher yield due to the higher conversion in the fermentor, but the lower production of hydrogen together with lower energy production makes this process less profitable even though they are environmentally more friendly in terms of cooling water and raw material consumption than the catalytic based processes.

Fig. 16. Raw material consumption(Fermentation)

Table 6.- Operating cost of 60Mgal/yr via fermentation

\section{Discussion of the optimal solution.}

From the previous section we can conclude that the flowsheet with lowest production cost, $\$ 0.41 / \mathrm{gal}$, is the one shown in Fig. 17 involving high pressure gasification, steam reforming, PSA for removal of hydrogen, a 
combined PSA followed by MEA system to remove $\mathrm{CO}_{2}$ and $\mathrm{H}_{2} \mathrm{~S}$, catalytic reactor and indirect distillation sequence. For this flowsheet, the yield to ethanol is $20 \%$ ( $\mathrm{kgethano}_{\text {o }} / \mathrm{kg}_{\text {biomass }}$ ) generating 18MW of energy and requiring 68MW of cooling. However, by selling hydrogen as a byproduct the operating cost drops from $\$ 1.04$ /gal down to $\$ 0.41$ /gallon. Table 7 summarizes the mass and energy balances of the optimal flowsheet. Fig. 18 shows the distribution of the cost. As it can be seen for $\$ 1.04 /$ gal, the raw material contributes to the price before credits up to $43 \%$, utilities, $6 \%$, annualized equipment, $40 \%$, chemicals (MEA, olivine), salaries and others $12 \%$. Table 8 shows a summary of the investment and the annual manufacturing costs which are respectively $\$ 335$ millions and $\$ 63.9$ millions/yr. Notice that the gasifiers are the most expensive equipment, followed by the compressors and the heat exchangers. For the manufacturing cost the raw material is the biggest share, followed by the annualized equipment cost, and utilities where the income for generated energy is already included. In spite of having a reduced yield to ethanol (20\%) compared to the thermo-biochemical processes, or even those using indirect gasification, the proposed design provides hydrogen as fuel or as raw material for the production of other fuels and allows some margin for the expected increase in the raw material cost.

Figure 17.- Optimal flowsheet.

Figure 18.- Cost distribution of optimal flowsheet.

Table 7.- Summary of the process (60MMgal/yr)

Table 8.- Summary of economic data of the optimal design

If we compare the final operating costs obtained in this work (see Tables 4 and 5) with the different values reported in the literature, the results are quite promising. We acknowledge that the values depend on the assumption of the different authors so the comparison are not totally consistent. Nevertheless, they can indicate approximate estimates which might still be helpful. Philips et al $(2007)^{18}$ reported a price for ethanol of $\$ 1.22 /$ gallon (with a reduction down to $\$ 1.01$ /gallon due to byproduct credits) via indirect gasification of lignocellulosic materials followed by steam reforming and high alcohols synthetic path. Dutta and Phillips $(2009)^{22}$ reported a price of $\$ 1.95 /$ gallon if direct gasification is used. Huhnke $(2008)^{19}$ reported the production of ethanol via gasification-fermentation at $\$ 1.2$ /gal. In both cases, these values can be improved. In fact, the Coskata process, based also on the fermentation of syngas, claims production costs under $\$ 1$ lgallon. ${ }^{23}$ However, the 
price of ethanol reported by Coskata can be reduced if we separate the hydrogen to be sold separately since their process does not consider this option.

Finally, it is important to mention that there are a uncertainties regarding the cost of the different raw materials, the hydrogen as well as the process itself. We now briefly discuss the effect of these parameters in the production process:

a) The increase of the price of the raw material affects the processes according to their use of raw material and ethanol and hydrogen yield. In case of an increase in the price of lignocellulosic switchgrass from $30 \$ / M T$ to $75 \$ / M T$, instead of using high pressure direct gasification, the low pressure gasification with steam reforming and catalytic path becomes the best alternative at the cost of $\$ 1.05 / \mathrm{gal}$

b) Selling prices of hydrogen lower than $1 \$ / \mathrm{kg}$ may change the flowsheet due to the high consumption of biomass by the high pressure gasifier. Lower hydrogen prices will make the processes based on the high pressure gasifier unattractive, while the production of ethanol (if the selling price remains the same) should be favored even by means of using reverse water gas shift to increase the yield of ethanol (from $32 \%$ to 38\%) with no production of hydrogen. However, the expectations of hydrogen as a future fuel makes its production a good asset for the supply chain of biofuel production. However, the biomass cannot only be a source of hydrogen but a source of carbon too. Thus, even though the economics of the hydrogen is important for the profitability of the process, the carbon from the biomass has to be used for the production of biofuels or chemicals.

c) Another topic is the concentration of ethanol in the fermentor. Further developments in the fermentation reaction (the bacteria, the fermentor itself) will make the processes based on that technology more competitive. Ideally, the concentration of ethanol in the reactor should be above $15 \%$. New technologies are in the development stage to capture the ethanol as it is produced so that the actual concentration in the liquid remains low (Nielsen and Prather, 2009). However, its applicability to industrial processes is still far into the future.

d) In the partial oxidation case, we assumed the same conversions as in the steam reforming. Although data from the literature have been used to support this assumption, a variation of $25 \%$ in the conversions, particularly that of methane, affects less that $7 \%$ in the hydrogen content in the 
gas phase which results an increase in the manufacturing cost up to $9 \%$ in the worst case, but it does not alter the decision upon the best process.

e) Equipment cost is another source of uncertainty. It is widely acknowledged that any costing correlation in the literature has at least $10-20 \%$ error. This translates into $8-16 \%$ error in the manufacturing costs presented in Tables 5 and 6 . Even though correlations from different sources have been used, the cost of the main equipment has been checked versus the data in the literature with good agreement.

f) Finally, the composition of the gas generated by the gasifiers may be uncertain since no experimental values for switchgrass gasification were found. However, the data used were based on lignocellulosic material for gasification ${ }^{18,30}$ and the gas composition was readjusted based on the feed composition.

\section{CONCLUSIONS}

The conceptual synthesis of process flowsheets for the production of ethanol from lignocellulosic materials via gasification has been investigated in this paper. The problem was formulated as a superstructure optimization problem for minimizing energy use, and where the alternatives that were evaluated include 2 gasifiers, 3 alternatives for composition adjustment, 3 technologies for sour acid removal, and two synthetic paths, fermentation with four dehydration possibilities and catalytic, with 2 alternative distillation sequences.

In order to solve the corresponding MINLP problem, a decomposition scheme has been proposed. The superstructure was partially decomposed in 8 subproblems in terms of choices for the gasifier, reforming mode and synthetic path. Each subproblem was divided into three subsystems linked by conditions of purity or composition of the streams at the entrance of each subsystem. The subsystems are solved as NLP's to provide the optimal clean-up, composition and purification technologies for each of the subproblems at minimum energy cost. The energy optimization of the different subproblems results in the fact that the surplus of hydrogen generated represents a major source of income leading to reduced cost of ethanol. The optimal flowsheet involves high pressure direct gasifier, steam reforming, removal of $\mathrm{H}_{2}, \mathrm{PSA}$ followed by MEA for the removal of sour acids, catalytic synthesis and indirect distillation sequence. The implementation of multieffect columns followed by heat integration of the hot and cold streams in the process provided a large reduction in energy consumption up to the point of generating energy instead of consuming it, improving the profitability of the 
process. The results are very encouraging because they indicate a potential cost of only $\$ 0.41 /$ gal when accounting for the income from the hydrogen as byproduct. Of course further detailed simulation and pilot plant studies must be performed in order to validate these results.

\section{ACKNOWLEDGMENTS}

The authors acknowledge NSF Grant CBET0966524 for financial support. Dr. M. Martín also acknowledges the financial support from the Ministry of Education and Science of Spain and Fulbright commission providing a MICINN - Fulbright Postdoctoral fellowship.

\section{REFERENCES}

1)Cole DE. Issues facing the Auto Industry: Alternative Fuels, Technologies, and Policies ACP Meeting Eagle Crest Conference Center June 20, 2007.

2) Shapouri H. Estimating the net energy balance of corn ethanol. In U.S. Department of Agriculture (USDA), Economic Research Service, Agricultural Economic Report No. 721., 1995.

3) Shapouri H, Duffield JA, Wang M, The energy balance of corn ethanol: an update: USDA, Office of Energy Policy and New Uses, Agricultural Economics. Rept. No. 813. 14 p., 2002.

4) Shapouri H, Duffield J, McAloon A, Wang, M. The 2001 Net Energy Balance of Corn-Ethanol (Preliminary): US Dept. Agriculture, Washington, DC. 2004

5) Pimentel D. Energy and dollar costs of ethanol production with corn: Hubbert Center Newsletter \#98/2, M. King Hubbert Center for Petroleum Supply Studies, Colorado Sch. Mines.Golden, CO. 7 p. 1998

6) Pimentel D. The limitations of biomass energy, in Meyers, R., ed., Encyclopedia of Physical Science and Technology. (3rd edn.), Vol. 2: Academic, San Diego, CA, 159-171, 2001

7) Pimentel D. Ethanol fuels: energy balance, economics, and environmental impacts are negative. Nat. Resour. Res., 2003, $12,2,127-134$

8) Ferguson ARB. Implications of the USDA 2002 update on ethanol from corn: The Optimum Population Trust, Manchester, U.K., 2003, 11-15.

9) Ferguson ARB. Further implications concerning ethanol from corn: Draft manuscript for the Optimum Population Trust, 2004

10) Elcock D. Baseline and Projected Water Demand Data for Energy and Competing Water Use Sectors, ANL/EVS/TM/088,2008

11) Huang J, Qiu H, Rozelle S, More pain ahead for China's food prices, Far Eastern Economic Review, 2008, 171, 5, 8-13.

12) Kszos LA. Bioenergy from switchgrass: reducing production costs by improving yield and optimizing crop management,

website: http://www.ornl.gov/ webworks/cppr/y2001/pres/114121.pdf (Nov. 29, 2006).

13) SenterNovem. Bioethanol in Europe Overview and comparison of production processes Rapport 2GAVE0601 www.senternovem.nl, 2006

14) Hamelinck CN, Geertje van Hooijdonk G, Faaij APC Ethanol from lignocellulosic biomass: techno-economic performance in short-, middle- and long-term. Biomass Bioenerg 2005, 28, 384-410 
15) Cardona CA, Sánchez OJ. Energy consumption analysis of integrated flowsheets for production of fuel ethanol from lignocellulosic biomass. 2006, Energy , 31, 2447- 2459

16) Zhang S, Marechal F, Gassner M, Perin-Levasseur Z, Qi W, Ren Z, Yan Y, Favrat D, Process Modeling and Integration of Fuel Ethanol Production from Lignocellulosic Biomass Based on Double Acid Hydrolysis. Energ Fuel, 2009, 23 (3), 17591765

17) Keshwani DR, Cheng JJ. Switchgrass for bioethanol and other value-added applications: A review Bioresour Technol 2009,100, 1515-1523

18) Phillips $S$, Aden A, Jechura J, Dayton D, Eggeman T. Thermochemical Ethanol via Indirect Gasification and Mixed Alcohol Synthesis of Lignocellulosic Biomass Technical Report, NREL/TP-510-41168, April 2007

19) Huhnke, R. L. Cellulosic ethanol using gasification-fermentation. Resource: Engineering \& Technology for a Sustainable World http://www.articlearchives.com/energy-utilities/renewable-energy-biomass/896186-1.html accessed Nov 172009

20) Piccolo C, Bezzo, F. A techno-economic comparison between two technologies for bioethanol production from lignocelluloses. Biomass Bioenerg, 2009, 33, $478-491$

21) Zhu $Y$, Gerber MA, Jones SB, Stevens DJ Analysis of the effects of compositional and configurational assumptions on product costs for the thermochemical conversion of lignocellulosic biomass to mixed alcohols FY 2007 Progress report. DOE PNNL.17949 Revision 1. 2009

22) Dutta A, Phillips SD Thermochemical Ethanol via Direct Gasification and Mixed alcohol Synthesis of Lignocellulosic Biomass. NREL/ TP-510-45913, 2009

23) Synbio http://www.synbio.org.uk/component/content/article/99-biotechnology-news/551-gm-and-coskata-claimcellulosic-ethanol-has-arrived-gasification-fermentation-process-yields-biofuel-for-under-1-per-gallon.html?directory=260 accessed Nov 17 2009,

24) Daichendt M, Grossmann IE. Integration of hierarchical Decomposition and mathematical programming for the synthesis of process flowsheets. Comp. Chem. Eng. , 1997, 22, 1-2, 147-175

25) Grossmann IE, Caballero JA, Yeomans, H. Mathematical Programming Approaches to the Synthesis of Chemical Process Systems, Korean J Chem Eng, 1999, 16, 407-426.

26) Rand DAJ, Dell RM. Hydrogen Energy Challenges and Prospects The Royal Society of Chemistry, Thomas Graham House, Science Park, Milton Road, Cambridge CB4 OWF, UK ISBN: 978-0-85404-597-6, 2008

27) Mani S, Tabil LG, Sokhansanj S. Grinding performance and physical properties of wheat and barley straws, corn stover and switchgrass Biomass Bioenerg 2004, 27, $339-352$

28) Bridgwater AV. Renewable fuels and chemicals by thermal processing of biomass. Chem. Eng. J. 2003, 91, 87-102

29) Di Blasi C. Modeling wood gasification in a countercurrent fixed-bed reactor. AIChE J.,. 2004, 50, 9, 2306-2319

30) Gissy J, Knight RA, Onischak M, Carty RH, Babu SP. Technology development and commercialization of the Renugas Process U.S. Finland Biofuels Workshop II. Espoo August 24-30, 1992

31) Brenes MD Biomass and bioenergy Nova Science Publishers, Incorporated ISBN-13: 9781594548659, 2006

32) Olofsson I, Nordin A, Söderlind U. Initial Review and Evaluation of Process Technologies and Systems Suitable for CostEfficient Medium-Scale Gasification for Biomass to Liquid Fuels Ingemar ISSN 1653-0551 ETPC Report 05-02

33) Martelli E, Kreutz T, Consonni S Comparison of coal IGCC with and without CO2 capture and storage: Shell gasification with standard vs. partial water quench. Energy Procedia, 2009, 1, 607-614

34) Neves CFC, Schvartzman MMAM Separaçao de CO2 per meio da tecnología PSA Quim. Nova, 2005, 28, 622-628 
35) Choi Y, Stenger HG. Water gas shift reaction kinetics and reactor modeling for fuel cell grade hydrogen $J$ Power Sources, 2003, 124, 432-439

36) (http://www.ist-world.org) November 2009

37) GPSA Engineering_Data_Book FPS VERSION 21-10, 2004

38) Reynolds S, Ebner A, Ritter J. New Pressure Swing Adsorption Cycles for Carbon Dioxide Sequestration Adsorption, 2005, 11, Suppl. 1, 531-536

39) Zhou L, Zhong L, Su W, Sun Y, Zhou, Y. Experimental Study of Removing Trace $\mathrm{H}_{2} \mathrm{~S}$ Using Solvent Coated Adsorbent for PSA, 2006, AIChE J., 52, 2066-2071

40) Li S, Martinek JG, Falconer JL, Noble RD, Gardner TQ. High-Pressure CO2/CH4 Separation Using SAPO-34 Membranes Ind. Eng. Chem. Res., 2005, 44 (9), 3220-3228

41) Klasson KT, Ackerson MD, Clausen EC, Caddy JL. (1991a) Mass transport in bioreactors for coal synthesis gas fermentation 1991a http://www.anl.gov/PCS/acsfuel/preprint\%20archive/Files/37 4 WASHINGTON\%20DC 08-92 1924.pdf May 2009

42) Nexant Inc. Equipment Design and Cost Estimation for Small Modular Biomass Systems, Synthesis Gas Cleanup, and Oxygen Separation Equipment Task 2: Gas Cleanup Design and Cost Estimates - Black Liquor Gasification Subcontract Report NREL/SR-510-39944 May 2006

43) Nexant Inc. Equipment Design and Cost Estimation for Small Modular Biomass Systems, Synthesis Gas Cleanup, and Oxygen Separation Equipment Task 9: Mixed Alcohols From Syngas - State of Technology Subcontract Report NREL/SR-510-39947 May 2006

44) Nexant Inc. Equipment Design and Cost Estimation for Small Modular Biomass Systems, Synthesis Gas Cleanup, and Oxygen Separation Equipment Task 2.3: Sulfur Primer Subcontract Report NREL/SR-510-39946 May 2006

45) Ko D, Siriwardane R, Biegler LT. Optimization of a Pressure-Swing Adsorption Process Using Zeolite 13X for CO2 Sequestration Ind. Eng. Chem. Res., 2003, 42 (2), 339-348

46) Klasson KT, Ackerson MD, Clausen EC, Gaday, JL. (1991b) Bioreactor design for synthesis gas fermentations, Fuel, $1991,70,5,605-614$

http://www.anl.gov/PCS/acsfuel/preprint\%20archive/Files/35 3 WASHINGTON\%20DC 08-90 0885.pdf May 2009

47) van Kasteren JMN, Dizdarevic, D, van der Waall WR, Guo J, Verberne R, Bio-ethanol from bio-syngas. Technical Report. Technische Universiteit Eindhoven (TU/e), Telos \& Ingenia Consultants \& Engineers № 0456372-R02, 2005

48) Nielsen DR, Prather KJ. Adsorption of second generation biofuels using polymer resins with in situ product recovery (ISPR) applications. Paper 564f AIChE Annual meeting 2009 Nashville.

49) Clausen EC, Gaddy JL. Ethanol from biomass by gasification / fermentation

http://www.anl.gov/PCS/acsfuel/preprint\%20archive/Files/38 3 CHICAGO 08-93 0855.pdf April 2009

50 ) BRI ENERGY William F. Bruce, President The Co-Production of Ethanol and Electricity From Carbon-based Wastes

51) Spath PL, Dayton DC. Preliminary Screening - Technical and Economic Assessment of Synthesis Gas to Fuels and Chemicals with Emphasis on the Potential for Biomass-Derived Syngas NREL/TP-510-34929, 2003

52) Biegler LT, Grossmann IE, Westerberg AW. Systematic Methods of Chemical Process Design, Prentice Hall, New Jersey, 1997

53) Karuppiah, R., Peschel, A., Grossmann, I.E., Martín, M., Martinson, W. Zullo, L. Energy optimization for the design of corn based ethanol plants. AICHE J,. 2008, 54, 1499-1525

54) Ladisch MR, Voloch M, Hong J, Blenkowski P, Tsao GT. Cornmeal Adsorber for Dehydrating Ethanol Vapors, Ind. Eng. Chem. Des. Dev., 1984, 23, 437-443. 
55) Beery KE, Ladisch MR Adsorption of Water from Liquid-Phase Ethanol-Water Mixtures at Room Temperature using Starch-Based Adsorbents, Ind. Eng. Chem. Res, 2001, 40, 2112-2115

56) Ladisch MR, Dyck K. Dehydration of Ethanol: New Approach Gives Positive Energy Balance Science,1979. 205, 898 900

57) Jacques K, Lyons TP, Kelsall DR. The Alcohol Textbook, 3rd ed.Nottingham, United Kingdom: Nottingham University Press, 1999.

58) Braisher M, Gill S, Treharne W, Wallace M, Winterburn J, Cui Z, Das DB, Snowdon C. Design Proposal. Bioethanol Production Plant. Project Report. May 2006

59) Larsson M, Zacchi G. Production of ethanol from dilute glucose solutions. A technical -economic evaluation of various refining alternatives. Bioproc. Eng. 1996,15, 125-132

60) Haelssig JB, Tremblay, AY, Thibault J. Technical and economic considerations for various recovery schemes in ethanol production by fermentation. Ind. Eng. Chem. Res, 2008, 47, 6185-6191

61) Linhoff B, Townsend DW, Boland D, Hewitt GF, Thomas BEA, Guy AR, Marsland RH. User Guide on Process Integration for the Efficient Use of Energy, Institution of Chemical Engineers, Rugby, England, 1982

62) Yee TF, Grossmann IE. "Simultaneous optimization models for heat integration - II. Heat exchanger networks synthesis". Comput. Chem. Eng., 1990, 28, 1165-1184.

63) Franceschin G, Zamboni A, Bezzo F, Bertucco A. Ethanol from corn: a technical and economical assessment based on different scenarios Chem. Eng. Res. Des., 2008, 86, 5, 488-498

64) Balat M, Balat H, Öz C. Progress in bioethanol processing Prog Energ Combust, 2008, 34, 5, 551-573

65) Lave LB, Griffin WG.The Green Bullet Foreign policy Posted March 2006

66) Dow Chemical Personal communication

67) DOE http://www.hydrogenassociation.org/general/fleet Module8.pdf $\quad$ accessed 2 may 2010

68) Smith R, Varbanov P. What's the price of Steam? CEP, 2005, July 29-33

69) Wei L, Pordesimo LO, Igathinathane $C$, Batchelor WD, Process engineering evaluation of ethanol production from wood through bioprocessing and chemical analysis. Biomass Bioenerg, 2009, 33, 255-266

70) Deutschmann O, Schmidt LD. Two-dimensional modeling of partial oxidation of methane on rhodium in a short contact time reactor Twenty-Seventh Symposium (International) on Combustion/The Combustion Institute, 1998/pp. 2283-2291

71) Vernon PDF, Green MLH, Cheetham AK, Ashcroft AT. Partial oxidation of methane to synthesis gas Catalysis Letters, $1990,6,2,181-186$

72) Sinnot RK. Coulson and Richardson, Chemical Engineering. 3ªd. Butterworth Heinemann, Singapur, 1999

73) Personal communication with Cargill 
Table 1. Data for adsorption on corn grits

\begin{tabular}{|c|c|}
\hline Parameter & Value \\
\hline$x_{\text {in,ads }}^{\text {ethanol,min }}$ & 0.77 \\
\hline$x_{\text {out,ads }}^{\text {ethanol,max }}$ & 0.977 \\
\hline ads $_{\text {adential }}$ Ads $\left.1{ }_{(\mathrm{kg} \text { water adsorbed }} / \mathrm{kg}_{\text {adsorbent }}\right)$ & 0.075 \\
\hline Working temperature $\left({ }^{\circ} \mathrm{C}\right)$ & 91 \\
\hline
\end{tabular}


Table 2. Data for molecular sieves

\begin{tabular}{|c|c|}
\hline Parameter & Value \\
\hline$x_{\text {in,MS }}^{\text {ethanol,min }}$ & 0.8 \\
\hline $\begin{array}{c}a d s_{\text {potential }} \text { MS } \\
\text { (kg water } / \mathrm{kg} \\
\text { adsorbent) }\end{array}$ & 0.08 \\
\hline$t_{-}$MS $_{\text {saturation }}(\mathrm{s})$ & 360 \\
\hline$r h_{\text {in,MS }}(\%)$ & 70 \\
\hline$r h_{\text {out,MS }}(\%)$ & 70 \\
\hline
\end{tabular}


Table 3.- Definition of subproblems

\begin{tabular}{|c|c|c|c|}
\hline Subproblem & Gasifier & Reforming & Synthesis \\
\hline$A$ & \multirow{4}{*}{ Low pressure indirect } & \multirow[t]{2}{*}{ Partial Oxidation } & Catalysis \\
\hline$B$ & & & Fermentation \\
\hline $\mathrm{C}$ & & Steam reforming & Catalysis \\
\hline $\mathrm{D}$ & & & Fermentation \\
\hline$E$ & \multirow{4}{*}{ High pressure direct } & \multirow[t]{2}{*}{ Partial Oxidation } & Catalysis \\
\hline $\mathrm{F}$ & & & Fermentation \\
\hline G & & \multirow[t]{2}{*}{ Steam reforming } & Catalysis \\
\hline $\mathrm{H}$ & & & Fermentation \\
\hline
\end{tabular}


Table 4.- Summary of the operating condition of the distillation multieffect columns

\begin{tabular}{|c|c|c|c|c|c|c|}
\hline Subproblem & Column & $\alpha$ & $\beta$ & $\mathrm{P}(\mathrm{LP}) \mathrm{mmHg}$ & LP/IP & $\mathrm{IP} / \mathrm{HP}$ \\
\hline \multirow{2}{*}{ (A) } & Col7 & 0.195 & 0.345 & 200 & 2.75 & 2.91 \\
\hline & Col8 & 0.151 & 0.348 & 200 & 2.75 & 2.91 \\
\hline \multirow{2}{*}{$\begin{array}{r}\text { (B) } 15 \% \text { Water } \\
5 \% \text { Water }\end{array}$} & Col3 & 0.058 & 0.2 & 200 & 2.75 & 2.91 \\
\hline & & 0.055 & 0.2 & 200 & 2.75 & 2.91 \\
\hline \multirow[t]{2}{*}{ (C) } & Col7 & 0.195 & 0.342 & 200 & 2.75 & 2.91 \\
\hline & Col8 & 0.152 & 0.342 & 200 & 2.75 & 2.91 \\
\hline \multirow{2}{*}{$\begin{array}{r}\text { (D) } 15 \% \text { Water } \\
5 \% \text { Water }\end{array}$} & Col3 & 0.058 & 0.2 & 200 & 2.75 & 2.91 \\
\hline & & 0.057 & 0.2 & 200 & 2.75 & 2.91 \\
\hline \multirow[t]{2}{*}{$(\mathrm{E})$} & Col7 & 0.232 & 0.349 & 200 & 2.75 & 2.91 \\
\hline & Col8 & 0.152 & 0.348 & 200 & 2.75 & 2.91 \\
\hline \multirow{2}{*}{$\begin{array}{r}\text { (F) } 15 \% \text { Water } \\
5 \% \text { Water } \\
\end{array}$} & Col3 & 0.058 & 0.2 & 200 & 2.75 & 2.91 \\
\hline & & 0.055 & 0.2 & 200 & 2.75 & 2.91 \\
\hline \multirow[t]{2}{*}{$(G)$} & Col7 & 0.232 & 0.349 & 200 & 2.75 & 2.91 \\
\hline & Col8 & 0.153 & 0.348 & 200 & 2.75 & 2.91 \\
\hline \multirow{2}{*}{$\begin{array}{r}\text { (H) } 15 \% \text { Water } \\
5 \% \text { Water }\end{array}$} & Col3 & 0.058 & 0.2 & 200 & 2.75 & 2.91 \\
\hline & & 0.058 & 0.2 & 200 & 2.75 & 2.91 \\
\hline
\end{tabular}

Legend: LP: Low pressure: IP: Intermediate pressure: HP: High pressure $\alpha$ : fraction of total feed to LP column $\beta$ : fraction of total feed to IP column 
Table 5.- Operating cost of $60 \mathrm{Mgal} / \mathrm{yr}$ via catalytic reaction

\begin{tabular}{|c|c|c|c|c|}
\hline & A & C & E & G \\
\hline & \multicolumn{2}{|c|}{ Low pressure Gas } & \multicolumn{2}{|c|}{ High pressure gas } \\
\hline Raw material contribution (\%) & 38.6 & 38.7 & 44.5 & 42.6 \\
\hline Utilities contribution (\%) & 7.6 & 8.0 & 0.8 & 6.0 \\
\hline Ethanol yield $\left(\mathrm{kg}_{\text {ethanol }} / \mathrm{kg}\right.$ biomass) & 0.26 & 0.26 & 0.20 & 0.20 \\
\hline Production cost $(\$ /$ gal) & 0.88 & $\mathbf{0 . 8 7}$ & 1.00 & 1.04 \\
\hline Prod. cost (Credits $\mathrm{H}_{2}$ ) (\$/gal) & 0.81 & 0.55 & 0.67 & $\mathbf{0 . 4 1}$ \\
\hline
\end{tabular}


Table 6.- Operating cost of 60Mgal/yr via fermentation

\begin{tabular}{|c|c|c|c|c|c|c|c|c|}
\hline & & & & & & & & \\
\hline & \multicolumn{4}{|c|}{ Low pressure gasification } & \multicolumn{4}{|c|}{ High pressure gasification } \\
\hline$\%$ Ethanol & $5 \%$ & $15 \%$ & $5 \%$ & $15 \%$ & $5 \%$ & $15 \%$ & $5 \%$ & $15 \%$ \\
\hline Raw material contribution (\%) & 26.3 & 32.9 & 25.6 & 30.8 & 32.6 & 34.4 & 32.0 & 35.6 \\
\hline Utilities contribution (\%) & 25.4 & 17.2 & 31.3 & 16.8 & 18.0 & 16.4 & 22.5 & 17.0 \\
\hline Ethanol yield ( $\left.\mathrm{kg}_{\text {ethanol }} / \mathrm{kg}_{\text {biomass }}\right)$ & 0.32 & 0.32 & 0.33 & 0.33 & 0.26 & 0.26 & 0.26 & 0.26 \\
\hline Production cost (\$/gal) & 1.05 & 0.84 & 1.04 & 0.87 & 1.06 & 1.01 & 1.07 & 0.97 \\
\hline Prod. cost (Credits $\left.\mathrm{H}_{2}\right)$ (\$/gal) & 0.96 & 0.75 & 0.81 & 0.64 & 0.84 & 0.79 & 0.62 & 0.51 \\
\hline
\end{tabular}


Table 7.- Summary of the mass and energy balances for the optimized process (60MMgal/yr)

\begin{tabular}{|l|c|}
\hline Raw material consumption (kg/s) & 29.1 \\
\hline Hydrogen produced (kg/s) & 0.79 \\
\hline Ethanol produced (kg/s) & 5.81 \\
\hline High Alcohols produced (kg/s) & 0.84 \\
\hline Energy (before integration) MW & 79 \\
\hline Energy (after integration) MW & -18 \\
\hline
\end{tabular}


Table 8.- Summary of economic data of the optimal design Costs

$\$ M M$

\begin{tabular}{lr}
\hline Total investment cost $^{72}$ & 335.16 \\
\hline & \\
Equipment distribution & $\$ \mathrm{MM}$ \\
\hline Solid treatment & 3.78 \\
Gas production & \\
(gasifier+reforming) & 32.38 \\
Gas purification & 2.93 \\
Compressors & 15.70 \\
Heat exchangers & 13.25 \\
Product syntesis and purification & 8.13 \\
\hline Net equipment cost & 76.18 \\
& \\
Manufacturing cost & $\$ \mathrm{MM} / \mathrm{yr}$ \\
\hline Equipment (ROI + depreciation) & 25.39 \\
Utilities & 7.49 \\
Utility credits & -3.65 \\
Salaries & 1.92 \\
General + Admin. & 1.71 \\
Chemicals & 1.16 \\
Maintenance & 1.50 \\
Swichgrass & 27.16 \\
Other expenses & 1.22 \\
Total & 63.92 \\
Hydrogen & -38.95 \\
\hline
\end{tabular}




\section{Figure Captions}

Figure 1.- Superstructure flowsheet for the production of lignocellulosic ethanol via gasification.

Figure 2.- Pretreatment

Figure 3.- Gasification alternatives

Figure 4.- Gas clean up

Figure 5.- Composition adjustment.

Figure 6.- Sour acid gases removal superstructure

Figure 7.- Syngas fermentation scheme

Figure 8.- Ethanol dehydration superstructure

Figure 9.- Flowsheet for the catalytic synthesis of ethanol

Figure 10.- Superstructure for the production of ethanol

Figure 11.- Decomposition of the superstructure.

Figure 12.- Superstructure for the multieffect columns: Legend: LP: Low pressure: IP: Intermediate pressure: HP:

High pressure $\alpha$ : fraction of total feed to LP column $\beta$ : fraction of total feed to IP column

Figure 13.- Optimized energy consumption (catalytic reactor)

Figure 14.- Raw material consumption (catalytic reactor)

Figure 15.- Energy optimzation (Fermentation)

Figure 16. Raw material consumption(Fermentation)

Figure 17.- Optimal flowsheet.

Figure 18.- Cost distribution of optimal flowsheet. 